Website : http://pilar.unmermadiun.ac.id/index.php/pilarteknologi

\title{
Pertimbangan Biaya Dalam Pemilihan Bekisting
}

\author{
Moh Arif Bakhtiar Efendi ${ }^{1)}$, Rendi Gusta Wibowo ${ }^{2)}$, \\ 1) Dosen Prodi Teknik Sipil, Fakultas Teknik, Universitas Merdeka Madiun 63133 \\ arifbakhtiar@unmer-madiun.ac.id \\ 2) Dosen Prodi Teknik Sipil, Fakultas Teknik, Universitas Merdeka Madiun 63133 \\ rendigusta@gmail.com
}

\begin{abstract}
Materials in the construction world is progressing quite rapidly. Likewise formwork as a project is also experiencing quite rapid progress which refers to the value of the results of a project. In a project the determination of the type of system and formwork method will affect the cost and time in progress, the selection of the formwork method which is not appropriate will have a loss in the future. The analysis conducted is comparing formwork of semi-conventional methods and system (PERI) in column, beam and plate formworks of the INKA Graha Building Construction Project, Madiun. The objective to be achieved in this paper is to find out the type of formwork that is efficient to be used in a formwork work both for beam and plate columns, in terms of cost comparisons and finding a draw point between the two methods.

After analyzing it is known that the use of semi-conventional initiating systems is more efficient with a value of Rp. 2,349,756,391, - and for the PERI system costs Rp. 3,050,649,782, - . The draw point of this system is in the volume of 31,500 $\mathrm{m} 2$ which means that in this volume the use of semi-conventional systems and PERI systems does not differ in terms of cost.
\end{abstract}

Keywords: formwork, konvensional, system (PERI), table form and cost.

\section{PENDAHULUAN}

Seperti material lain yang digunakan pada dunia konstruksi mengalami kemajuan yang cukup pesat. Demikian juga bekisting sebagai bahan untuk mewujudkan suatu proyek juga mengalami kemajuan yang cukup pesat yang mengacu pada nilai hasil sebuah proyek.

Pada suatu proyek besar penentuan jenis sistem dan metode bekisting ini akan berpengaruh pada biaya dan waktu dalam pengerjaan, jangan sampai pemilihan metode bekisting yang kurang tepat bisa membuat dampak kerugian di kemudian hari. Penggunaan alat dan material bekisting akan lebih efisien karena bisa dipindah dan dipakai lagi setelah pengecoran. Maka dari itu perencanaan pemilihan jenis bekisting harus direncanakan dengan matang sehingga waktu penyelesaian pekerjaan bekisting dapat diperkirakan serta mengurangi pemborosan baik dari segi sumber daya manusia maupun pemakaian alat dan material yang digunakan.

Perencanaan, pengawasan dan pelaksanaan yang baik serta melakukan metode evaluasi akan dapat mengantisipasi kerugian pada pekerjaan bekisting ini. Pembangunan Gedung Graha INKA Madiun dalam perencanaannya memiliki 4 lantai dengan bentuk struktur yang bisa dikatakan typical sehingga memudahkan sirkulasi material dan alat dikarenakan bentuk yang relatif sama antara lantai 1 dan lainnya. Dengan demikian ada beberapa metode bekisting yang bisa diterapkan disini baik menggunakan bekisting konvensional maupun table form, maka dari itu dibutuhkan evaluasi dalam pemilihan metode yang paling efektif dan efisien.

Bertolak dari permasalahan tersebut penulis akan melakukan penelitian tentang pemilihan bekisting yang efisien dan pencarian titik pemakaian yang mempunyai nilai biaya yang sama antara beksiting konvensional dan system PERI.

\subsection{Tujuan Penelitian}

Dengan mengacu latar belakang yang telah dipaparkan, pada penelitian ini dapat dirumuskan tujuan penelitian yaitu membuat pertimbangan ekonomis dalam pemilihan jenis bekisting yang ekonomis pada proyek ini dan kondisi proyek yang mempunyai titik biaya yang sama untuk kedua jenis bekisiting yang direncanakan.

\subsection{Tinjauan Pustaka}

Adapun pengertian bekisting ialah cetakan yang dipakai pada pekerjaan pengecoran hingga menghasilkan suatu bentuk tertentu. Sedangkan perancah adalah struktur bangunan sementara yang 
Website : http://pilar.unmermadiun.ac.id/index.php/pilarteknologi

berfungsi menopang bekisting, agar tidak berubah selama proses pengecoran. Bahan bekisting dapat dibuat dari bahan kayu, logam atau pasangan bata, sedangkan perancah dapat dibuat dari bambu, kayu atau logam (Yusron, 2010).

Menurut Blake (1975), ada beberapa aspek yang harus diperhatikan pada pemakaian bekisting dalam suatu pekerjaan konstruksi beto yakni:

1. Kualitas bekisting yang akan digunakan harus tepat dan layak serta sesuai dengan bentuk pekerjaan struktur yang akan dikerjakan.

2. Keamanan bagi pekerja konstruksi tersebut, maka bekisting harus cukup kuat menahan beton.

3. Biaya pemakaian bekisting yang harus direncanakan sehemat mungkin

\subsubsection{Pertimbangan Ekonomis}

Untuk mengurangi biaya bekisting, metoda yang dapat digunakan ialah dengan menggunakan bekisting dan perancah secara berulang-ulang.

Bekisting dengan menggunakan lapisan pelindung pada permukaannya dapat memperpanjang umur pemakaian. Fungsi lapisan pelindung pada permukaan adalah agar campuran beton ketika mengeras tidak melekat sehingga sukar untuk dilepaskan. Lapisan pelindung pada permukaan dapat berupa bahan minyak, kapur, plastik dan bahan admixture.

Hal yang juga penting adalah proses pembukaan serta pemeliharaan perancah dan bekisting. Cara pembukaan yang sembarang akan memperpendek umur pakai, demikian sebaliknya dengan pemeliharaan yang baik akan memperpanjang umur pakai dan sekaligus meningkatkan jumlah pengulangan pemakaian serta menurunkan biaya pekerjaan ini. (Yusron, 2005)

Bekisting merupakan kompenen biaya terbesar dalam pekerjaan struktur bertingkat yang tipikal. Biaya bekisting berkisar $40 \mathrm{~s} / \mathrm{d} 60$ persen dari total biaya beton dan untuk perkiraan 10 persen dari total biaya konstruksi.

Proporsi biaya yang besar dari bekisting konvensional relatif terhadap biaya upah bekisting. Pengurangan biaya yang signifikan dapat dicapai dengan pengurangan biaya upah. (Hanna, 1999)

\subsubsection{Bekisting PERI}

Sistem PERI merupakan bagian dari pekerjaan bekisting sistem. Elemen- elemen dari sistem ini dibuat di pabrik dan diaplikasikan pada bangunan yang bersangkutan dengan elemen-elemen pembantu yang merupakan bagian dari sistem ini. Karena aplikasinya sudah sangat disederhanakan, segi teknisnya pun menjadi cukup ringan, akan tetapi pembelian elemen-elemen dari sistem ini memerlukan biaya yang cukup tinggi (Setiaty, 2005).

Sistem PERI mulai diperkenalkan di Indonesia sejak 1985 seperti layaknya sebuah sistem yang baru, pada awal perkembangannya sistem tersebut di Indonesia mengalami masa-masa sulit, terutama hal ini disebabkan masih sulitnya merubah kebiasaan kontraktor di Indonesia untuk menerima suatu hal yang baru, berbeda dengan sistem konvensional. Baru setelah melalui beberapa kali uji pakai pada beberapa proyek, ada sebagian kontraktor yang mulai tertarik pada sistem tersebut.

Saat ini sistem PERI sudah banyak digunakan dalam pekerjaan bekisting pada gedung-gedung bertingkat atau pekerjaan sipil lainnya. Salah satu hal yang membuat sistem ini banyak dipakai dibandingkan dengan sistem konvensional, adalah karena dalam pemakaiannya lebih mudah dibongkar pasang dan lebih bebas sampah (Hidayat, 2002).

Metode bekisting dengan sistem PERI sangatlah praktis dan mudah dalam pemasangan serta pembongkarannya. Elemen-elemen penyusun bekistingnya tersedia sangat detail mulai dari balokbalok girder, asesoris sabuk waller sampai ke asesoris yang kecil didesain sedemikian rupa sehingga dapat diaplikasikan dengan mudah (Nofirman, 2006).

\section{METODE PENELITIAN}

Analisis data menggunakan metode analitis dan deskriptif. Analitis berarti data yang sudah ada diolah sedemikian rupa sehingga menghasilkan hasil akhir yang dapat disimpulkan. Sedangkan deskriptif maksudnya adalah dengan memaparkan masalah-masalah yang sudah ada atau tampak serta kesimpulan dari hasil analisis. 
Adapun diagram alir penelitian adalah sebagai berikut :

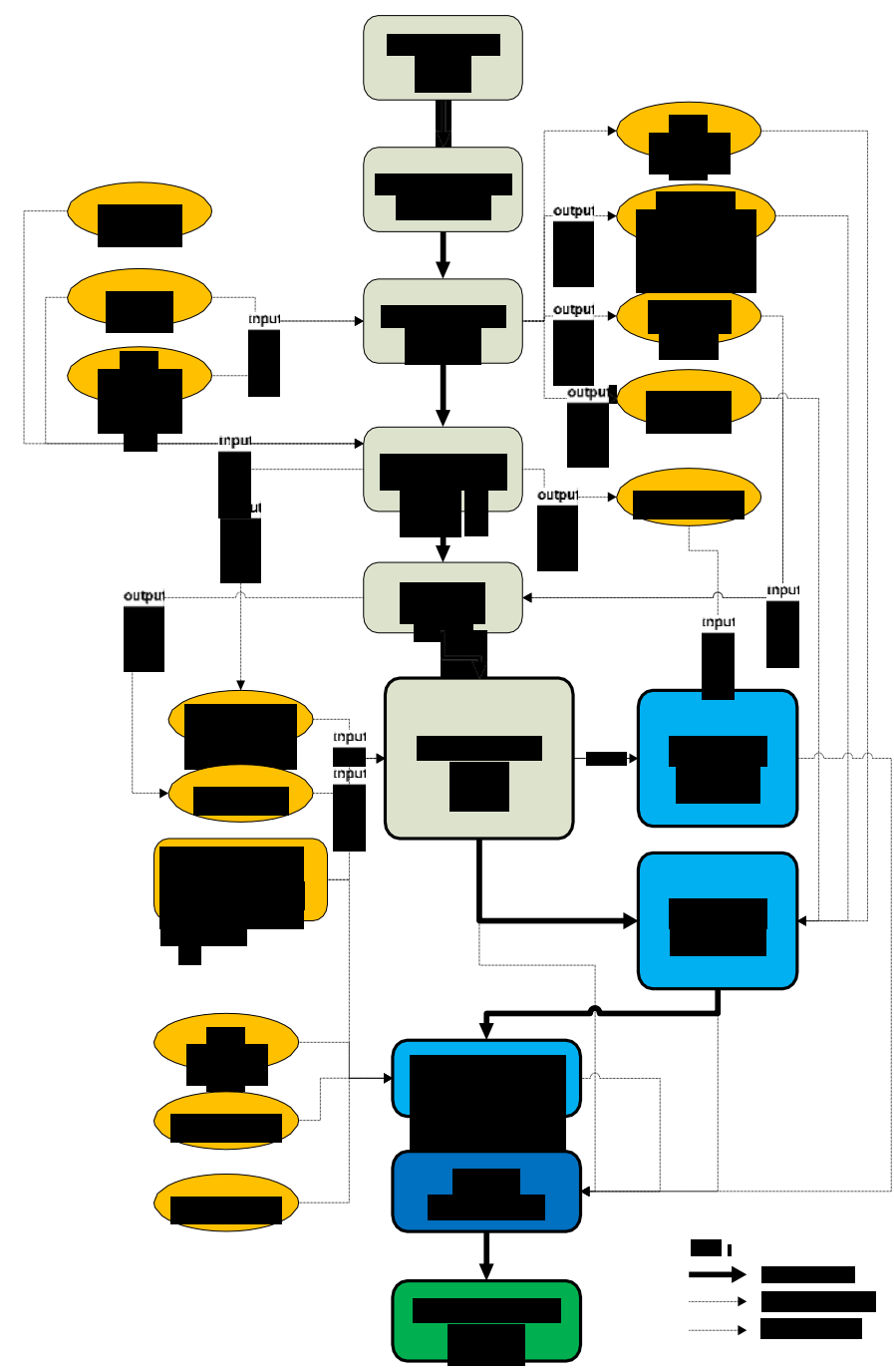

Gambar 1. Diagram Alir Analisis (Mardal, 2008)

\section{HASIL DAN PEMBAHASAN}

Penggunaan material bekisting ditujukan untuk memperoleh biaya yang ekonomis. Mengingat pekerjaan bekisting merupakan sebuah konstruksi sementara disini akan dirincikan antara sistem bekisting semi konvensional dengan sistem table form, dengan membandingkan pada sistem perancahnya saja mengingat sistem bekisting kolom pada dimensi $70 \times 70$ mengharuskan penggunaan sistem PERI Girder semua.

Perhitungan biaya bekisitig semi konvensional:

$$
n=\frac{(q x r \times t)+(q x r x t \times w)+(l \times v)+c+m}{v}
$$

- Jumlah Alat

- Harga sewa

- Konsumabel 
Website : $\underline{\text { http://pilar.unmermadiun.ac.id/index.php/pilarteknologi }}$

- Lama Sewa

- Upah Tenaga kerja

- Luas Bekisting

- Harga bekisting per $\mathrm{m}^{2} \quad$ : (n)

- Waist (0.05)

- Mobilisasi $:(\mathrm{t})$

Hasil perhitungan biaya bekisting balok sistem konvensional adalah :

$n=\frac{(144.444 .300)+(7.222 .215)+\left(40.000 x 7.198,37 m^{2}\right)+(332.925 .000)}{7.198 .37 m^{2}}$

$$
7.198,37 \mathrm{~m}^{2}
$$

$\mathrm{n}=$ Rp. $107.320 / \mathrm{m}^{2}+$ ppn $10 \%$

$\mathrm{n}=\mathrm{Rp} .118 .052,-$

Dari harga diatas kontraktor mengambil keuntungan sebesar $15 \%$ yang didalamnya sudah termasuk cadangan biaya resiko sebesar 2.5\%-5\%. Maka harga bekisting semi konvensional untuk pembangunan gedung Graha INKA Madiun adalah Rp. $118.052+\left(15 \%\right.$ x 118.052) $=$ Rp. $135.759 / \mathrm{m}^{2}$

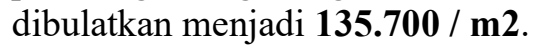

Atau dengan luasan pekerjaan balok 7.198,37 $\mathrm{m}^{2}$ maka jumlah biaya bekisting keseluruhan untuk pekerjaan balok yaitu Rp. 976.818.809,-

Hasil perhitungan biaya bekisting plat sistem konvensional adalah :

$n=\underline{(307.213 .238)+(15.360 .662)+\left(40.000 \times 8.126 .94 \mathrm{~m}^{2}\right)+(170.450 .000)}$

$\mathrm{n}=$ Rp. $100.665 / \mathrm{m}^{2}+\mathrm{ppn} 10 \%$

$8.126,94 \mathrm{~m}^{2}$

$\mathrm{n}=$ Rp. 110.732,-

Dari harga diatas kontraktor mengambil keuntungan sebesar $15 \%$ yang didalamnya sudah termasuk cadangan biaya resiko sebesar 2.5\%-5\%. Maka harga bekisting semi konvensional untuk pembangunan adalah Rp. $110.732+\left(15 \%\right.$ x 110.732) $=$ Rp. $127.342 / \mathrm{m}^{2}$ dibulatkan menjadi $\mathbf{1 2 7 . 3 0 0} /$ m2.

Atau dengan luasan pekerjaan plat 8.126,94 $\mathrm{m}^{2}$ maka jumlah biaya bekisting keseluruhan untuk pekerjaan plat yaitu Rp. 1.034.559.462,-

Perhitungan Biaya bekisting Sistem Table Form:

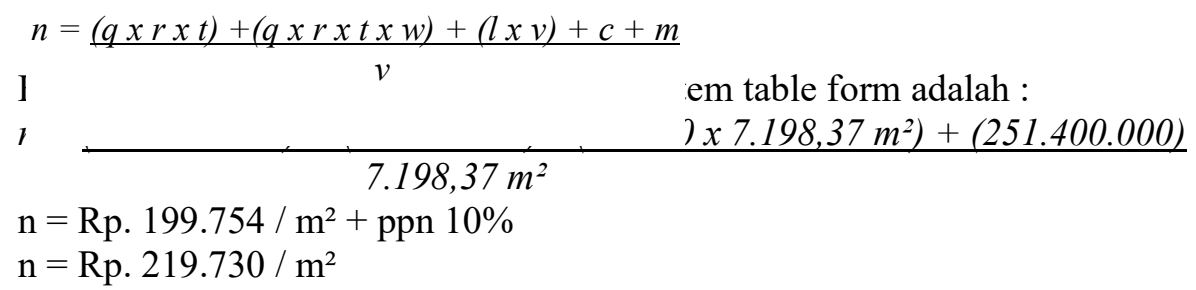

Dari harga diatas kontraktor mengambil keuntungan sebesar $15 \%$ yang didalamnya sudah termasuk cadangan biaya resiko sebesar 2.5\%-5\%. Maka harga bekisting sistem table form untuk pembangunan gedung Graha INKA Madiun adalah Rp. $219.730+(15 \%$ x 219.730 $)=$ Rp. $252.690 / \mathrm{m}^{2}$

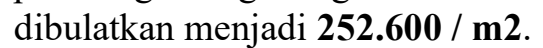

Atau dengan luasan pekerjaan balok 7.198,37 $\mathrm{m}^{2}$ maka jumlah biaya bekisting balok keseluruhan yaitu Rp. 1.818.308.262,--

Hasil perhitungan biaya bekisting plat sistem table form adalah :

$n=\underline{(233.280 .000)+(6.998 .400)+\left(40.000 \times 8.126,94 \mathrm{~m}^{2}\right)+(141.500 .000)}$ $8.126,94 \mathrm{~m}^{2}$

$\mathrm{n}=$ Rp. $86.977 / \mathrm{m}^{2}+$ ppn $10 \%$

$\mathrm{n}=$ Rp. $95.675 / \mathrm{m}^{2}$ 
Website : $\underline{\text { http://pilar.unmermadiun.ac.id/index.php/pilarteknologi }}$

Dari harga diatas kontraktor mengambil keuntungan sebesar $15 \%$ yang didalamnya sudah termasuk cadangan biaya resiko sebesar 2.5\%-5\%. Maka harga bekisting sistem table form untuk pembangunan gedung Graha INKA Madiun adalah Rp. $95.675+\left(15 \%\right.$ x 95.675) $=$ Rp. $110.026 / \mathrm{m}^{2}$ dibulatkan menjadi $\mathbf{1 1 0 . 0 0 0 / \mathbf { m } 2}$.

Atau dengan luasan pekerjaan balok 8.126,94 $\mathrm{m}^{2}$ maka jumlah biaya bekisting plat keseluruhan yaitu Rp. 893.963.400,-

Perhitungan Biaya Bekisting Kolom Sistem PERI Girder:

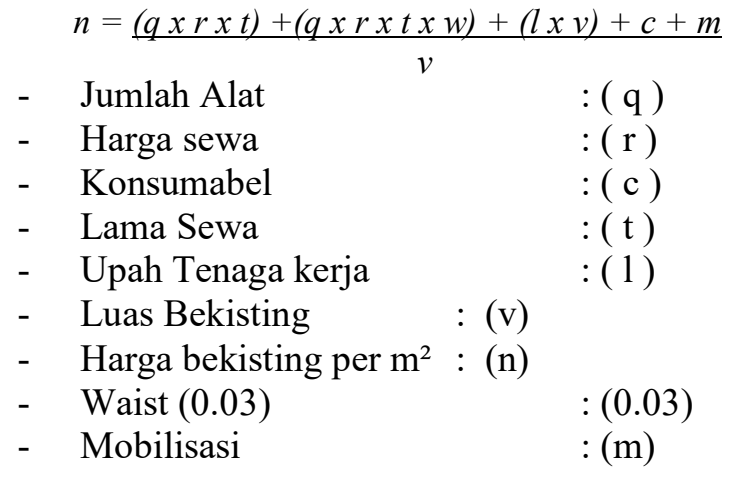

Hasil perhitungan biaya bekisting kolom sistem PERI adalah :

$n=\frac{(91.708 .320)+(2.751 .250)+\left(40.000 \times 2.696,24 \mathrm{~m}^{2}\right)+(65.220 .800)}{2.696,24 \mathrm{~m}^{2}}$

$\mathrm{n}=$ Rp. $99.223 / \mathrm{m}^{2}+$ ppn $10 \%$

$\mathrm{n}=$ Rp. $109.146 / \mathrm{m}^{2}$

Dari harga diatas kontraktor mengambil keuntungan sebesar $15 \%$ yang didalamnya sudah termasuk cadangan biaya resiko sebesar 2.5\%-5\%. Maka harga bekisting sistem table form untuk pembangunan gedung Graha INKA Madiun adalah Rp. $109.146+\left(15 \%\right.$ x 109.146) $=$ Rp. $125.518 / \mathrm{m}^{2}$

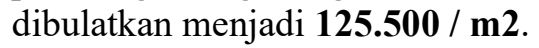

Atau dengan luasan pekerjaan balok 2.696,24 $\mathrm{m}^{2}$ maka jumlah biaya bekisting kolom keseluruhan yaitu Rp. 338.378.120,-

\section{Titik biaya yang sama dua system begkisting}

Dari perhitungan didapatkan bahwa perbedaan terbesar pemakaian antara 2 sistem berada di volume total (balok+kolom+plat) $18.000 \mathrm{~m} 2$ dengan selisih lebih dari Rp 700.000.000,- sedangkan titik biaya yang sama pemakaian 2 system ini berada di volume $31.500 \mathrm{~m} 2$ yang berarti bahwa pada volume ini pemakaian sistem konvesional maupun system PERI tidak berbeda dari segi biaya. Namun pada pemakaian lebih dari ini pemakaian system PERI lebih murah dibandingkan dengan pemakaian system konvensional. Bisa di lihat pada volime $36.000 \mathrm{~m} 2$ sistem konvensional memerlukan anggaran sekitar Rp. 4.447.000.000,- sedangkan system PERI membutuhkan anggaran sekitar Rp 4.075.000.000,- 


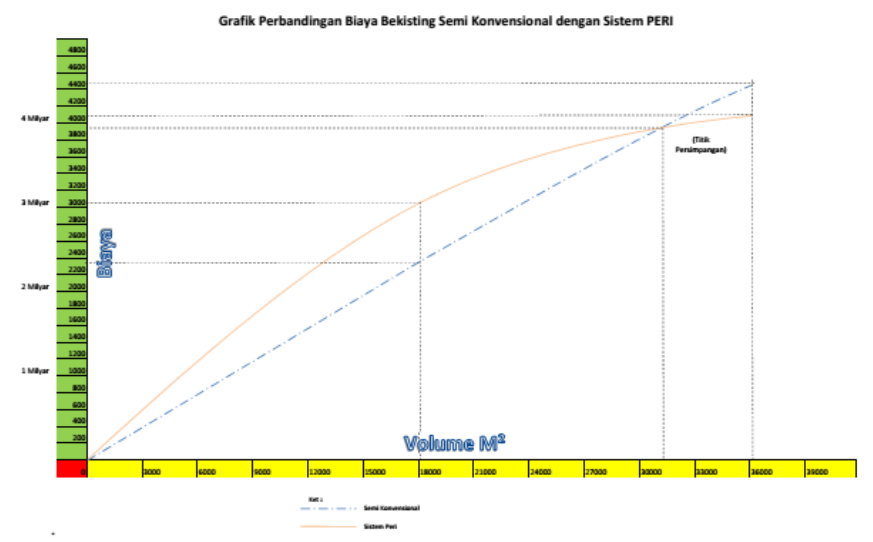

Grafik 1. Titik Imbang Pemakaian Sistem Konvensional dan Sisitem

\section{KESIMPULAN DAN SARAN}

Kesimpulan yang didapat bahwa penggunaan sistem semi konvensional lebih murah dibandingkan dengan system PERI dengan hasil perhitungan bekisitng system semi konvensional membutuhkan biaya Rp. 2.349.756.391,- dan untuk sistem PERI membutuhkan biaya Rp. 3.050.649.782,--.

Titik biaya yang sama dua system bekisting ini berada di volume $31.500 \mathrm{~m} 2$ yang berarti bahwa pada volume ini pemakaian sistem konvesional maupun system PERI tidak berbeda dari segi biaya.

Pembuatan sistem dengan alternatif material lain yang lebih efisien dan hemat tetapi mengutamakan kekuatan dan keamanan bekisting perlu di lakukan dengan harapan dapat menurunkan biaya.

\section{DAFTAR PUSTAKA}

Amri, Sjafei, 2005, "Teknologi Beton A-Z”, Jakarta : Yayasan John Hi-Tech Idetama Arikunto,S, 1993, "Prosedur Penelitian Suatu Pendekatan Praktik", Jakarta: Rineka Cipta Blake, L.S. 1975, "Civil Engineer's Referennce Book", London : The Butterwth \& Co. Ltd. Callahan, 1992, "Construction Project Schedulling." Singapore: McGraw Hill.

Clark, J. E., 1983, "Structural Concrete Cost Estimating." New York: McGraw Hill Book Company. Diphohusodo, 1994, "Struktur Beton Bertulang", Jakarta : Gramedia.

Handbook Formwork, 2005, "Successful Construction with PERI." PERI. Hanna, A. S., (1999), "Concrete Formwork System." University of Wisconsin : Marcel Dekker,inc.

Hidayat, I., 2002, "Perbandingan Perfoma antara Bekisting Beton Sistem Konvensional dengan Bekisting Beton Sistem PERI". Skripsi, Fakultas Teknik Universitas Indonesia, Depok.

Illingworth, J. R., 1993, “Construction Method and Planning." London: E \& FN Spon.

Mardal, M.,2008, "Optimalisasi Waktu dan Biaya Pekerjaan Bekisting untuk Gedung Bertingkat dengan Sistem Zoning (Studi Kasus: Proyek Shangri-la Hotel Condominium Jakarta." Skripsi, Fakultas Teknik Universitas Indonesia, Depok.

Nofirman, A., 2006, "Perbandingan Efisiensi, Efektifitas dan Ekonomis Metode Bekisting antara Sistem Konvensional dengan Sistem PERI.” Skripsi, FT Universitas Pancasila, Jakarta.

PKKI 1961 "Peraturan Konstruksi Kayu Indonesia NI-5". Badan Standarisasi Nasional

Setiaty, W., 2005, "Perbandingan Perancah Bekisting Box Girder antara Sistem PERI dengan Sistem

Ring Scaffold Ditinjau dari Segi Biaya dan Waktu.” Skripsi, FT Universitas Pancasila, Jakarta.

Stephens, 1985 "Pengertian Bekisting" http:/e-journal.uajy.ac.id.

Suripto, 2000,'Petunjuk Praktek Kerja Acuan dan Perancah I". Depok: Politeknik Negeri Jakarta. 
Website : $\underline{\text { http://pilar.unmermadiun.ac.id/index.php/pilarteknologi }}$

Yusron A., 2010, "Optimalisasi Waktu dan Biaya Pekerjaan Bekisting melalui sistem siklus pemakaian dan sistem zoning pada gedung bertingkat (Studi Kasus Proyek universitas gadjah mada kampus jakarta)." Skripsi, Fakultas Teknik Universitas Indonesia, Depok.

Wigbout, Ing. 1987, "Bekisting (Kotak Cetak)". Jakarta : Erlangga.

www.peri.com 